\title{
A correlation of thin lens approximation to thick lens design by using context based method in optics education
}

O. Farsakoglu, Ipek Inal Atik, Hikmet Kocabas

O. Faruk Farsakoglu, Ipek Inal Atik, Hikmet Kocabas, "A correlation of thin lens approximation to thick lens design by using context based method in optics education," Proc. SPIE 9289, 12th Education and Training in Optics and Photonics Conference, 928902 (17 July 2014); doi: 10.1117/12.2068368

SPIE Event: 12th Education and Training in Optics and Photonics Conference, 2013, Porto, Portugal 


\title{
A correlation of thin lens approximation to thick lens design by using context based method in optics education
}

\author{
O. Faruk Farsakoglu ${ }^{*}$, Ipek Inal Atik ${ }^{\mathrm{a}}$, Hikmet Kocabas ${ }^{\mathrm{b}}$ \\ ${ }^{a}$ Kilis 7 Aralik University, Faculty of Engineering and Architecture, Electrical and Electronics \\ Engineering Department, Kilis, Turkey; ${ }^{b}$ İstanbul Technical University. Faculty of Mechanical \\ Engineering, CAD CAM Center, Gumussuyu, Istanbul, Turkey
}

\begin{abstract}
The effect of Coddington factors on aberration functions has been analysed using thin lens approximation with optical glass parameters. The dependence of spherical aberration on Coddington shape factor for the various optical glasses in real lens design was discussed using exact ray tracing for the optics education and training purposes. Thin lens approximation and thick lens design are generally taught with only lecturing method. But, thick lens design is closely related to the real life. Hence, it is more appropriate to teach thin lens approximation and thick lens design with real-life context based approach. Context based teaching can be effective in solving problems in which the subject is very difficult and irrelevant. It also provides extensive evidence for optics education that students are generally unable to correctly apply the concepts of lens design to optical instruments currently used. Therefore, the outline of real-life context based thick lens design lessons were proposed and explained in detail considering thin lens approximation.
\end{abstract}

Keywords: Coddington shape factor, Coddington position factors, spherical aberration, lens design, context based method

\section{INTRODUCTION}

Lens design, also called optical design and optical system design, is the science or art of developing optical systems to image, direct, analyze, or measure light. These systems include: camera lenses, telescopes, microscopes, scanners, photometers, spectrographs, interferometers, eyepieces, and so forth. In most cases, it is desirable that these systems be as free of geometrical optical errors as possible. These geometrical errors are called aberrations. Correcting and controlling aberrations is one of the main tasks of the lens designer ${ }^{1}$. Lenses are theoretically considered to have no central thickness in geometrical optics. But in fact it is not able to occur that a lens can be without thickness in the real lens design.

The education of thick lens design exists in the curriculum of optics schools or in the special topics of physics education after graduating from the physics department. The most important part of the optics education is to teach thick lens design because it is the transformation of theoretical knowledge into practice. In other words, thick lens design means real lens design and it is used to design the lenses available in equipments used in the real life.

Practical lens design could be difficult to learn and teach both for students and staff because of the complexity of the topic. The teaching method of thick lens design course can be developed with new pedagogical approaches depending on the programs. The real life context based approach is integrated into the thick lens design course because its context focuses on the application of thin lens approximation theory.

Thin lens approximation and thick lens design are generally taught with only lecturing method. But especially, thick lens design is closely related to the real life. Hence, it is more appropriate to teach the thin lens approximation and thick lens design with real-life context based approach.

Students often succeed at problems related to everyday life at which they may fail in formal settings. They do better at problems expressed in everyday or familiar context rather than a scientific one ${ }^{2}$. Real life context designs are seen as creative and dynamic designs that engage exploration, join conceptual and procedural knowledge- both through thought and action; and can encourage considerations to technology, human and environmental interactions ${ }^{3}$.

*ffarsakoglu@kilis.edu.tr; phone 00903488142666 ext 1806

12th Education and Training in Optics and Photonics Conference, edited by

Manuel F. P. C. Martins Costa, Mourad Zghal, Proc. of SPIE Vol. 9289, 928902

(C) 2014 SPIE, OSA, IEEE, ICO·doi: 10.1117/12.2068368

Proc. of SPIE Vol. $9289928902-1$ 
To show the variation of spherical aberration with the Coddington shape factor may be quite significant in terms of understanding the effect of lens shape parameters on the spherical aberration. However, the most important point of thick lens design is to minimize the spherical aberration. Minimization of spherical aberration depends on especially glass selection and the precision of the optical system. If the system is precise, then the minimization should be at the optimum level.

The characteristics of spherical aberration depending on Coddington factors were used by considering the study in ref. 11 , in this context based approach. Certainly, different characteristics can be used in this approach for optics education and training purposes.

This study includes the variations of spherical aberrations with the values of Coddington shape factor in thin lens approximation. In the second step, it is clarified that the spherical aberrations of lenses change with the values of Coddington shape factor for the various optical glasses in the real lens design for the purpose of education. Therefore, the aim of the study is to investigate a teaching model for the outline of real life context based thick lens design lessons.

\section{BACKGROUND}

With a well-chosen combination of optical parameters such as lens shapes, number of optical elements, and different optical materials, aberrations in real optical systems can be reduced to a minimum or may be able to be eliminated to levels of requirements ${ }^{4}$. This is the most important part of optical design and it is very difficult for the instructor to teach. It is also hard to understand and for students to apply. Therefore, thin lens approximation is used in thick lens design instructions in order to simplify the subject which is suitable for the students.

In order to show students the relevance of optical design within optics education, a good introduction should define thin lens approximation.

\subsection{Thin Lens Approximation}

Aberrations are unfavourable conditions for the performance of lenses which will be designed. Monochromatic aberrations in general, primary (fourth order) wave or third order ray aberrations can be minimized according to desired purposes. When a single lens is considered, commonly only spherical aberration computations are performed in lens design. The minimization of other aberrations can be taken into consideration in the optical system. Principally, it is very useful to evaluate aberrations and their parameters for thin lenses in the first step. The primary wave aberration function for a thin lens which has the positive focal length is given as follows ${ }^{5-8}$.

$W(r, \theta ; \eta)=C_{s} r^{4}+C_{c} \eta r^{3} \operatorname{Cos} \theta+C_{a} \eta^{2} r^{2} \operatorname{Cos}^{2} \theta+C_{d} \eta^{2} r^{2}$

where the exit pupil is at the lens. $\mathrm{r}$ and $\theta$ are the polar coordinates at the exit pupil, and $\eta$ is the image height at the Gaussian image plane. The coefficients $\mathrm{C}_{\mathrm{s}}, \mathrm{C}_{\mathrm{c}}, \mathrm{C}_{\mathrm{a}}$, and $\mathrm{C}_{\mathrm{d}}$ represent the coefficients of spherical aberration, coma, astigmatism, and field curvature respectively. These coefficients in Eq. (1) may be given as follows;

$$
\begin{aligned}
& C_{S}=-\left[32 n(n-1) f^{3}\right]^{-1}\left[\frac{n+2}{n-1} S^{2}+(3 n+2) P^{2}+4(n+1) S P+\frac{n^{3}}{n-1}\right] \\
& C_{C}=\left[4 n i^{2}\right]^{-1}\left[\frac{n+1}{n-1} S+(2 n+1) P\right] \\
& C_{a}=-\left[2 i^{2} f\right]^{-1} \\
& C_{d}=-(n+1)\left[4 n i^{2} f\right]^{-1}
\end{aligned}
$$


where $\mathrm{n}$ is the refractive index of the optical glass, $\mathrm{f}$ is the paraxial focal length, and $\mathrm{i}$ is the image distance. The coefficient of distortion or wave front tilt is non-existent taking into account the exit pupil at the lens ${ }^{7}$. In terms of the coefficient $\mathrm{C}_{\mathrm{s}}$ and $\mathrm{C}_{\mathrm{c}}$ given by Eqs. (2.a) and (2.b) $\mathrm{S}$ and $\mathrm{P}$ are called Coddington shape factor (CSF) and Coddington position factor $(\mathrm{CPF})$ respectively. Coddington shape factor $\mathrm{S}$ determines the amount of curving as a function of the radii; $R_{1}$ and $R_{2}$, and is given by

$\mathrm{S}=\frac{\mathrm{R}_{2}+\mathrm{R}_{1}}{\mathrm{R}_{2}-\mathrm{R}_{1}}$

Each value of S describes the physical shape of the lens. The contributions of lens surfaces for refractions are determined in accordance with lenses having negative or positive focal lengths. Coddington position factor $\mathrm{P}$ is given by

$$
P=\frac{i+o}{i-o}
$$

where $\mathrm{i}$ is the image distance and o is the object distance. Each value of $\mathrm{P}$ indicates the location of the usage of the lens in the optical system. As seen in Eqs. (2.a) and (2.b), the spherical aberration and coma of the lens depend on CSF's and CPF's. On the other hand, the coefficients of astigmatism and field curvature which are represented by Eqs. (2.c) and (2.d) do not depend on CSF's and CPF's for the exit pupil at the lens. Therefore, these coefficients were not mentioned in this study. The differentiation of Eq. (2.a) by $\mathrm{S}$ which equals to zero gives the minimum spherical aberration corresponding to $\mathrm{S}_{\min }$ and the relationship between $\mathrm{S}_{\min }$ and Coddington position factor $\mathrm{P}$.

As an application, when the formulation given above is applied to the optical glasses and other lens materials, the results can be evaluated. In addition, this can also be expanded to thick lenses. The variations of lens characteristics for optical glasses were obtained at the Yellow Hellium line $(587.5618 \mathrm{~nm})$ in the applications. The glass designation is used at the same wavelength in our study. The glass designation has six digit numbers to describe optical specifications. The first three digits indicate the refractive index, and the second three digits represent the Abbe value. By using Eq.(2.a) and $\mathrm{S}_{\min }$, the variations of minimum spherical aberrations with CSF values can be obtained. However, zero spherical aberration for the glasses with the glass designations of 464658, 517642, 785258, and 952204 occurs at absolute CPF values of $4.85,4.46,3.31$, and 2.92 respectively. For minimizing spherical aberration, to realize the computation at the infinite conjugate ratio, $\mathrm{P}=-1$, is a useful procedure in terms of analysing the results. In this case, the variations of spherical aberrations with CSF values for various optical glasses are given in Fig.1. As shown in this figure every parabola has a value $\left(\mathrm{S}_{\min }, \mathrm{C}_{\mathrm{smin}}\right)$ of its vertex for the parallel light incident and it is seen that parabolas vary symmetrically and the parabola shape and vertex strongly depend on CSF and refractive index values.

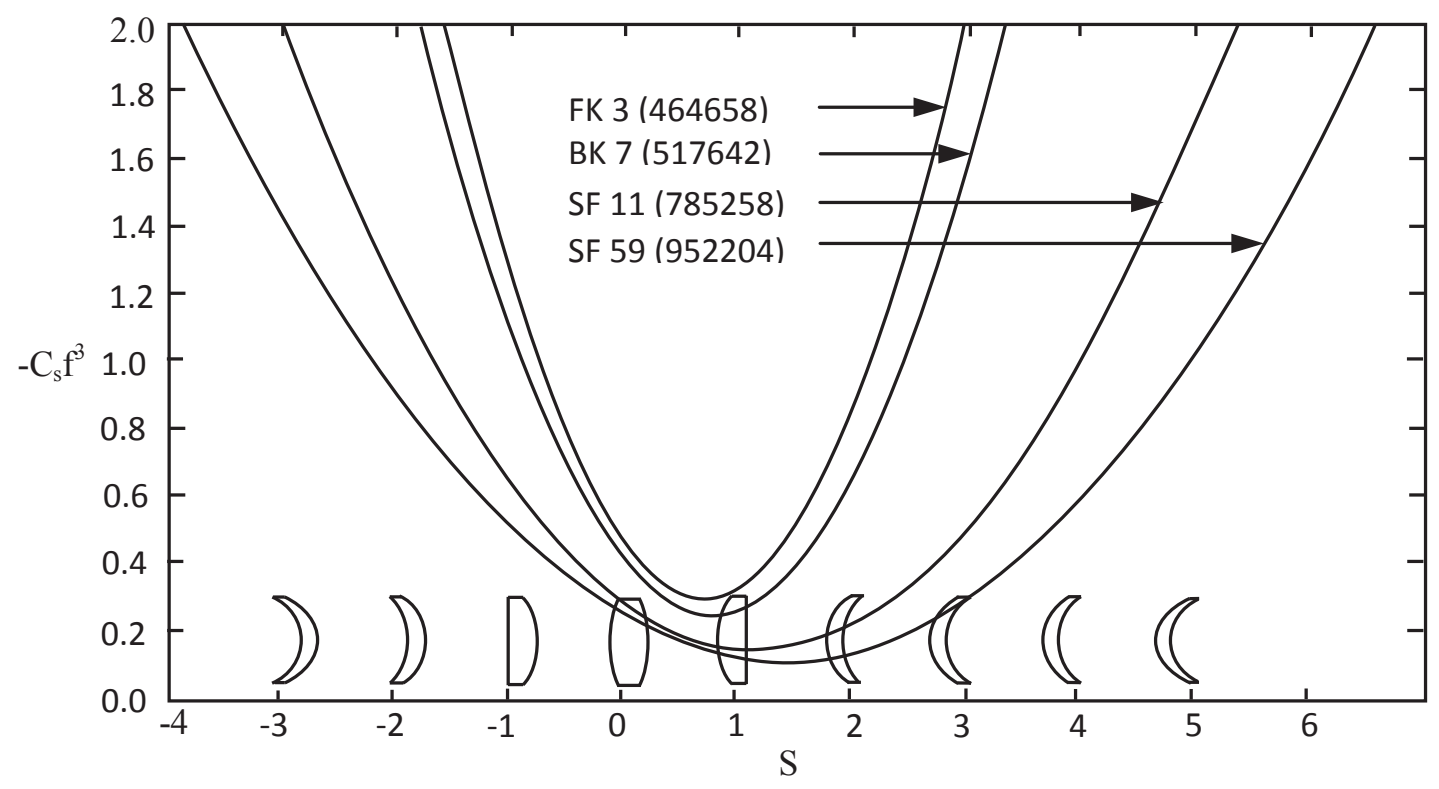

Figure 1. The variations of spherical aberrations with CSF values for various crown and flint optical glasses. 
In order to vanish coma as an aberration, the term in brackets at the right hand side in Eq.(2.b) which equals zero gives the spherical aberration with zero coma corresponding to $\mathrm{S}_{\mathrm{cz}}$ and the relationship between $\mathrm{S}_{\mathrm{cz}}$ and the Coddington position factor $\mathrm{P}$. For instance, for the parallel light incident variations of $\mathrm{S}_{\min }$ and $\mathrm{S}_{\mathrm{cz}}$ with the refractive indices of the various lens materials are given in Fig.2. As a practical application, the lens which is designed to obtain zero coma will have the minimum spherical aberration corresponding to $\left(\mathrm{S}_{\min }=\mathrm{S}_{\mathrm{cz}}\right)^{5,6}$. As an example, a lens having this condition can be used as the telescope objective to cover a rather small field of view ${ }^{9}$. On the other hand, the best solution may be that the lens possesses the most possible minimum spherical aberration and the lens is designed by considering the coma values corresponding to this case. Therefore, the residual coma values can be compensated within the optical system.

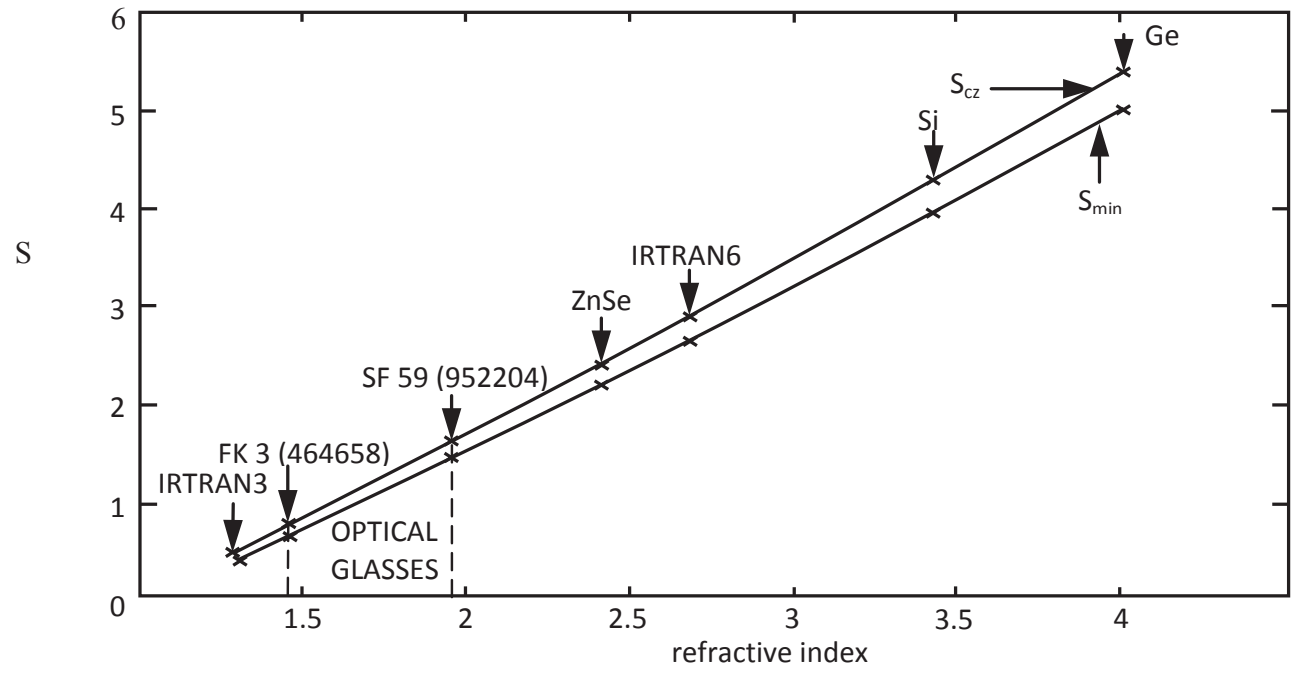

Figure 2. The variations of $\mathrm{S}_{\mathrm{cz}}$ and $\mathrm{S}_{\min }$ with refractive indices of optical glasses at the wavelength of $587.5618 \mathrm{~nm}$ and various IR lens materials at the wavelength of $10.6 \mu \mathrm{m}$.

\subsection{Thick Lenses}

As known, lens aberrations considerably depend on the uses of lenses, lens shapes, and lens materials. The variations of longitudinal spherical aberration (LSA) and transverse spherical aberration (TSA) with CSF values for positive and negative singlet lenses are given in Fig.3. The positive lenses which have the glass designation of 517642 have the same paraxial focal length of $75.00 \pm 0.02 \mathrm{~mm}$ and the central thickness of $4.00 \pm 0.01 \mathrm{~mm}$, and operate at f/ 3.00 (exit pupil at the lens) and an infinite conjugate ratio, $\mathrm{P}=-1$. The negative lenses which have the glass designation of 717295 have the same paraxial focal length of $-100.00 \pm 0.02 \mathrm{~mm}$, the central thickness of $2.00 \pm 0.01 \mathrm{~mm}$, operate at $\mathrm{f} / 4.00$ (exit pupil at the lens) and an infinite conjugate ratio, $\mathrm{P}=-1$. The variations of LSA with the CSF values for positive and negative singlet lenses made of various optical glasses are given in Fig.4. As an example in this application, positive lenses which have the glass designations of 464658, 517642, 785258, and 952204 have the same paraxial focal length, central thickness, and operate at the same relative aperture and conjugate ratio of the positive lenses in Fig.3. Negative lenses which have the glass designations of 517642, 673322, 762265, and 805254 have the same paraxial focal length, central thickness and operate at the same relative aperture and conjugate ratio of the negative lenses in Fig.3. The aberrations have been also computed and observed for positive and negative singlet lenses at the same conditions in Fig.3.

The evaluation of Coddington factors in the case of minimizing spherical aberration for positive singlet lenses may be outlined considering Fig.5. The CSF values of positive lenses which have the minimum spherical aberration are given in Fig.5 (a) and (b). Those lenses which have the variation of the shapes from asymmetric biconvex to meniscus form may be called "best singlet shape". The asymmetric biconvex form has the CSF value of about 0.64 for the glass with the designation of 464658. The meniscus form has the CSF value of about 1.44 for the glass with the designation of 952204 . These forms are quite acceptable for on-axis imaging. Furthermore, beyond the refractive index of optical glasses, the 
best shape lenses become the meniscus shape more curved in the IR region. The minimum LSA's with CSF values of positive best lens shape for the common lens materials used in the IR region are given in Fig. 6 (a) and (b).

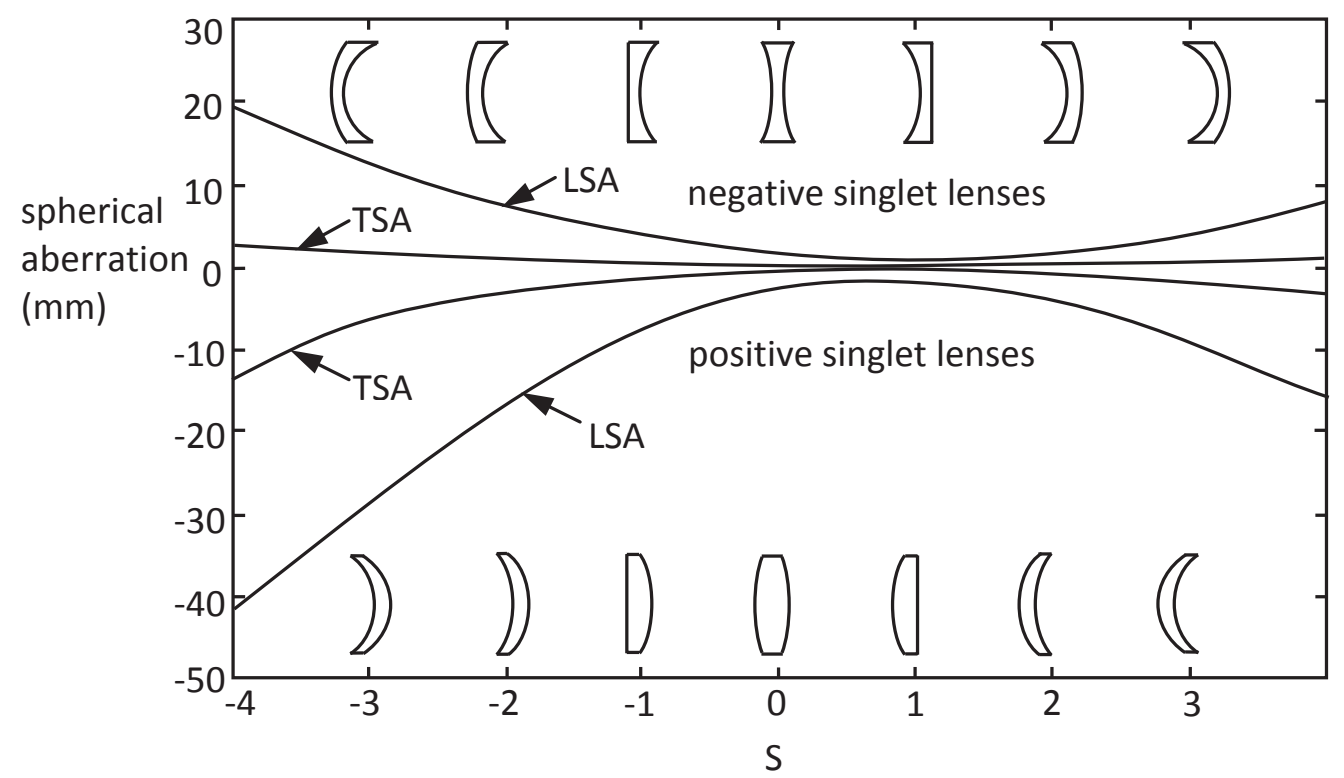

Figure 3. The variations of longitudinal and transverse spherical aberrations with CSF values for positive and negative singlet lenses. The positive and negative singlet lenses have respectively the same paraxial focal length, central thickness, and relative aperture (f/ $\phi$ ).

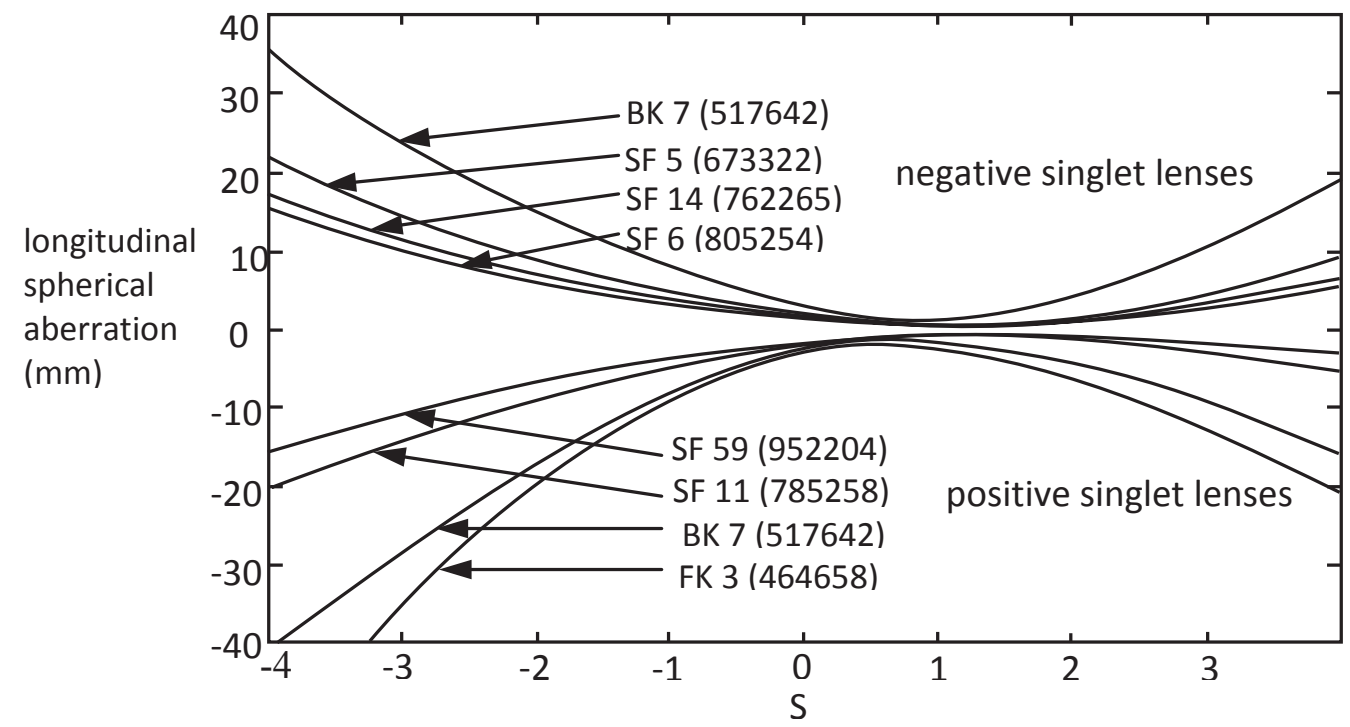

Figure 4. The variations of longitudinal spherical aberration with CSF values for positive and negative singlet lenses. 


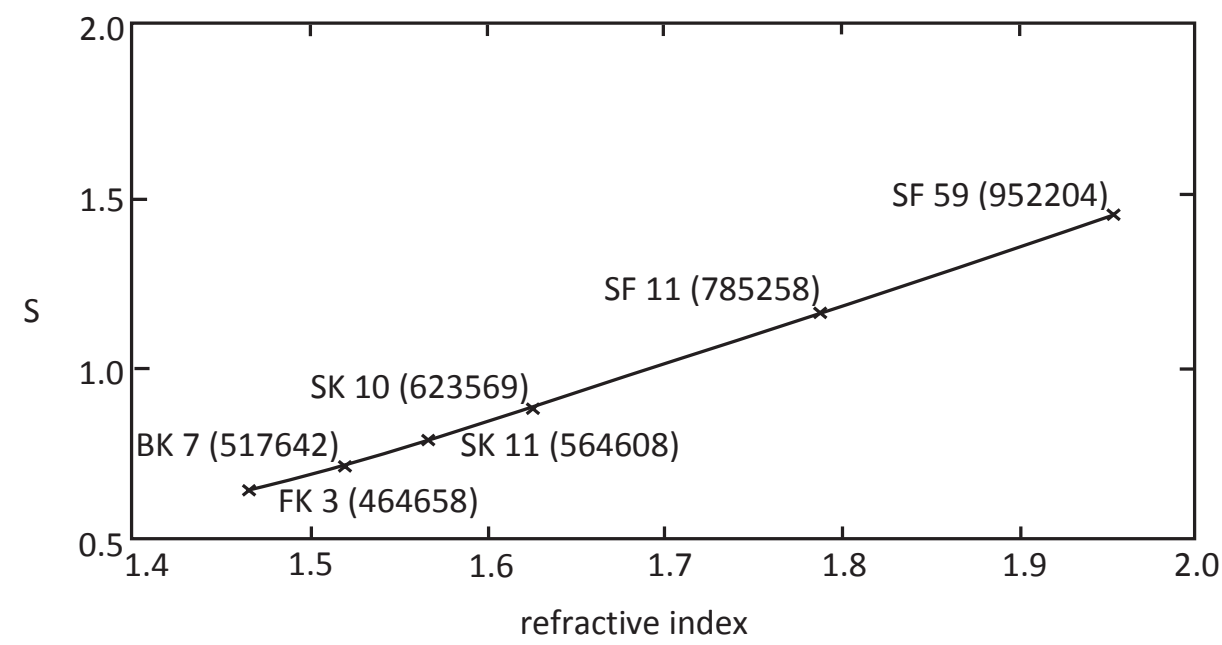

(a)

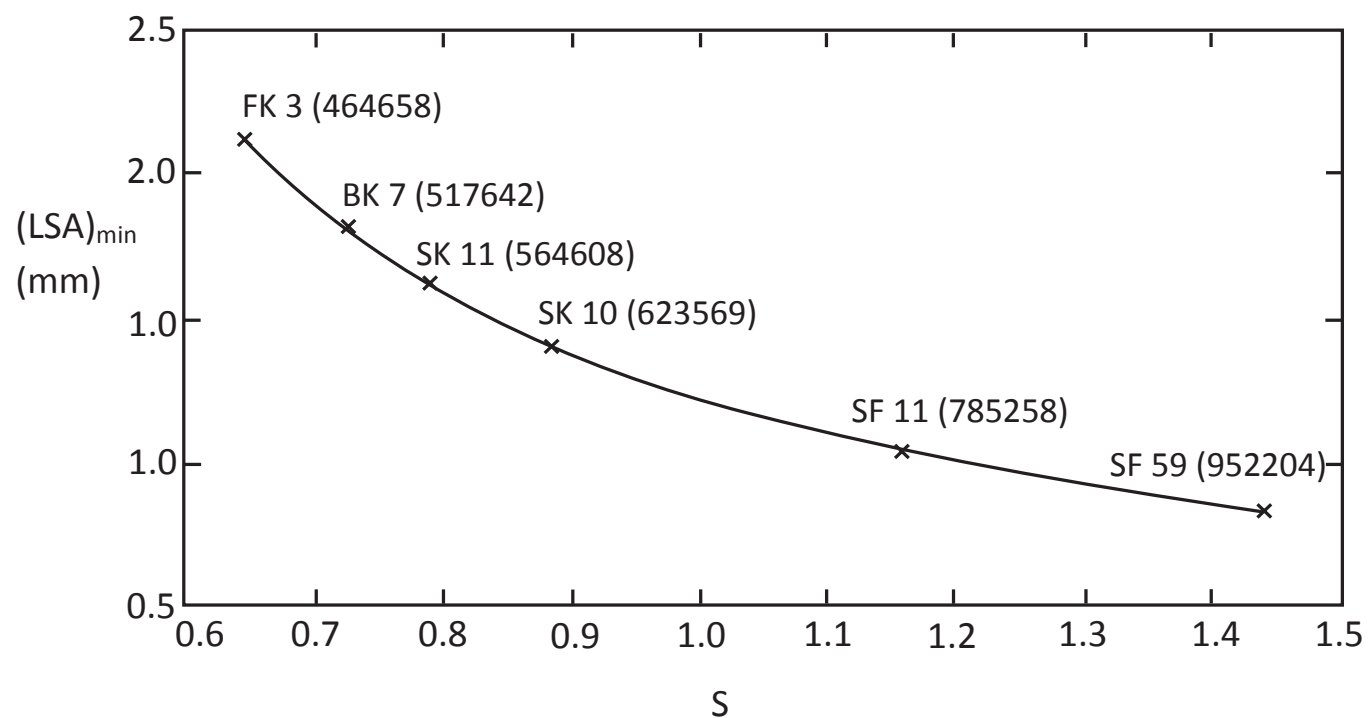

(b)

Figure 5. (a)The variation of CSF values for best lens shape with refractive indices, (b)The variation of (LSA) $\min$ 's with CSF values for best lens shape. The optical glasses having designations of 464658, 517642, 564608, 623569, 785258 , and 952204 are indicated on both curves 


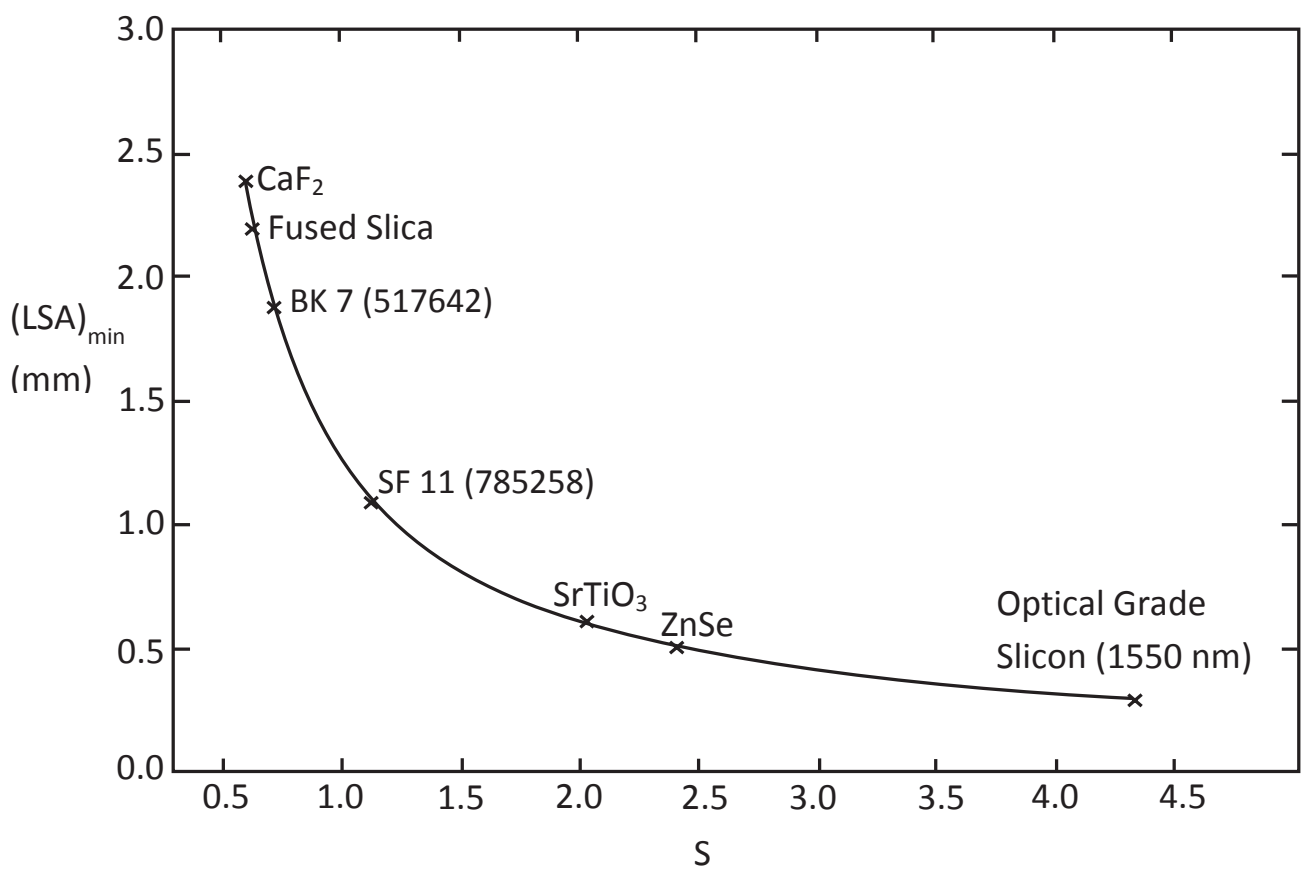

(a)

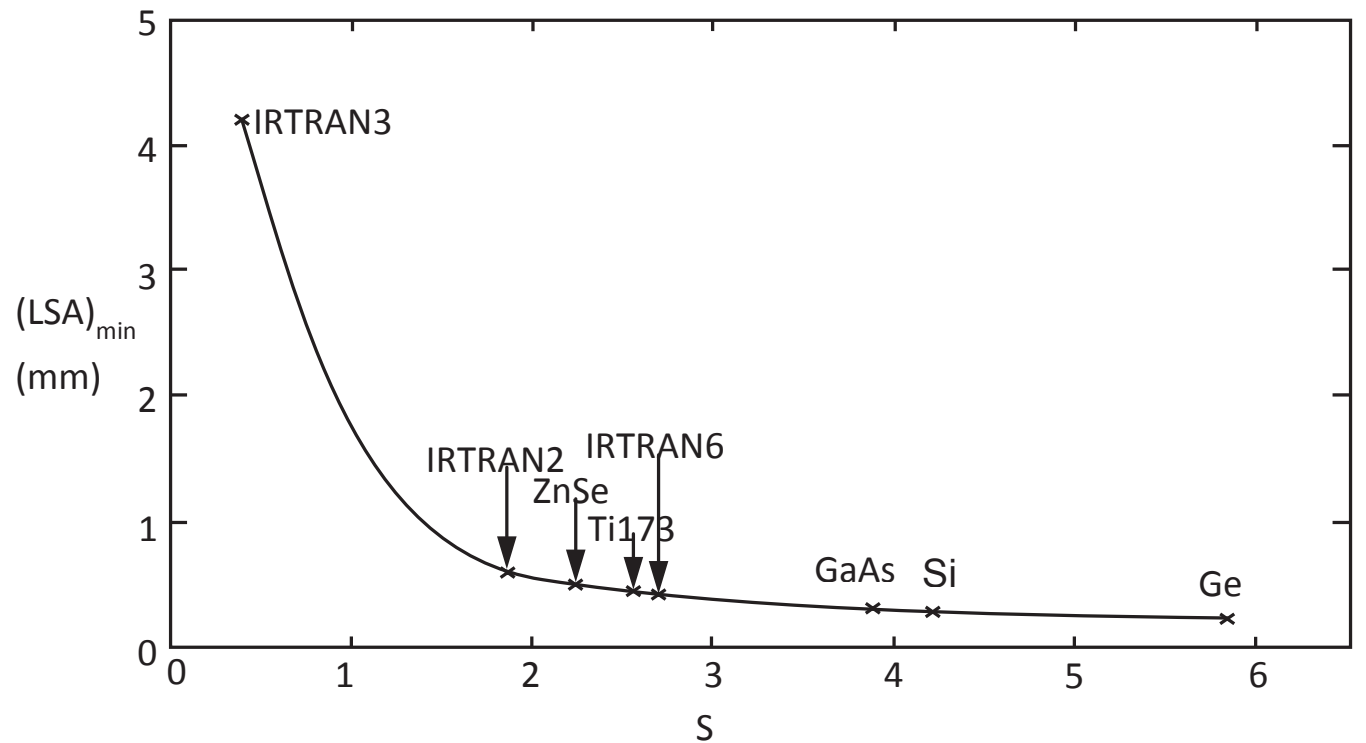

(b)

Figure 6. (a) and (b); the variations of minimum LSA's with CSF values of positive best lens shape for common IR lens materials which are used in IR regions. All lenses have the same paraxial focal length, central thickness, clear aperture, and operate at the same conditions of positive lenses in Fig.5.

In this case, the CPF has the value of -1.00. The positive singlet lenses become plano-convex for the CSF value of 1.00 and the CPF value of -1.00 . As an example, best shape lenses at the value of approximately 1.69 of the refractive index [Fig.5(a)] having the optical glasses; SF (8,15), BaSF13, KzFS 7A, BaF 50, LaF (20, N23), and LaK (9, N13, N14, 31) as indicated in the refractive index/Abbe value diagram ${ }^{10}$ have this form. As the dependency of the usage for the unit 
magnification, the symmetric biconvex lenses having the CSF value of 0.00 are the best shape. In this case, the CPF has the value of 0.00 . On the other hand, the Coddington factors of negative singlet lenses may be evaluated in similar case of positive lenses.

The variations of longitudinal spherical aberrations with CSF values for increasing central thickness of positive singlet lenses made of the flint glass having the designation of 785258 are given in Fig.7. As shown in the variations, the longitudinal spherical aberration against the central thickness tends to vary nonlinearly. The disorder of the parabola symmetry is caused by the effect of CSF values and the existence of the central thickness on the spherical aberration. Lens central thickness values can be defined for the appropriate lens edge thickness values. Thereby, using these central thickness values, the curve of LSA versus S can be obtained for the purpose of optical glass optimization ${ }^{11}$.

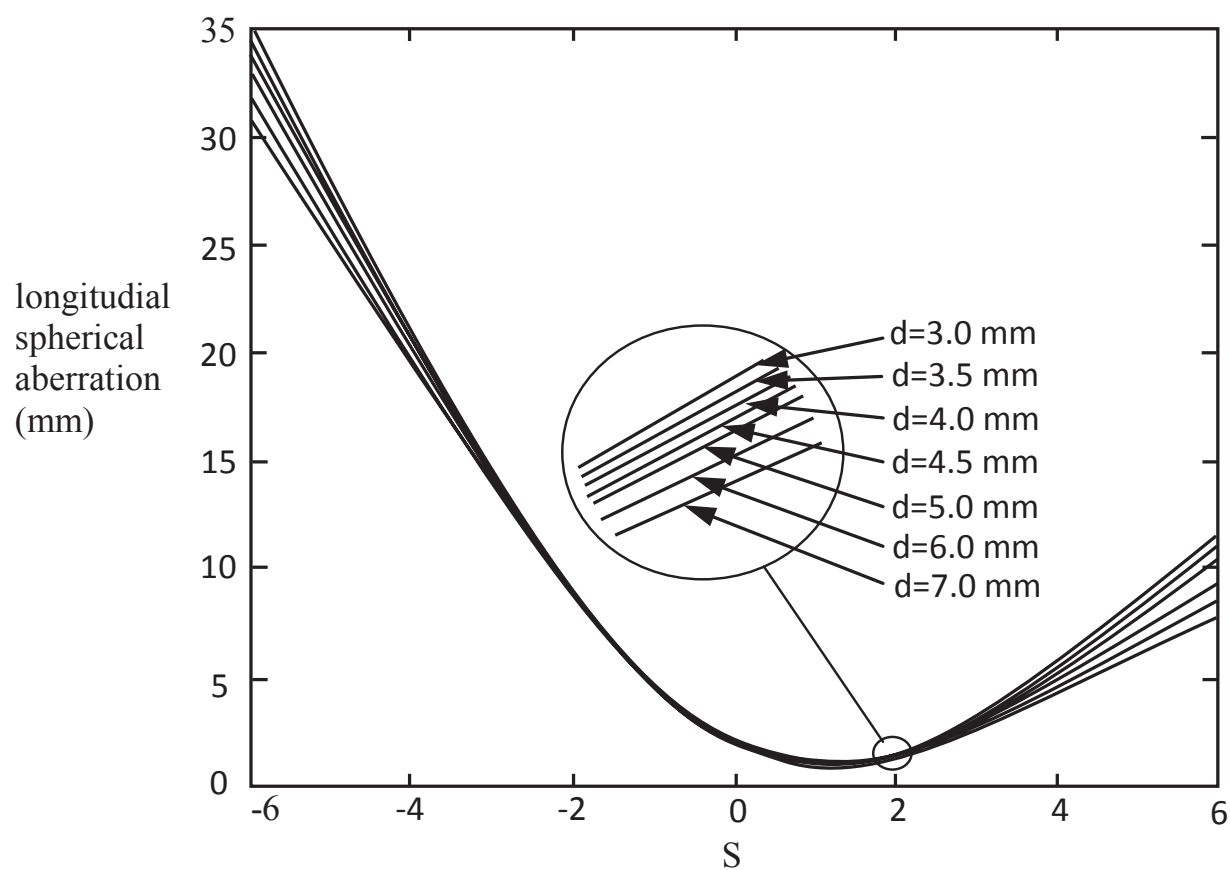

Figure 7. The variations of LSA's with CSF values for the various central thicknesses of positive singlet lenses made of the optical glass which have the designation of 785258. The paraxial focal lengths and clear aperture diameters of the lenses are the same at the values of $75.00 \pm 0.02 \mathrm{~mm}$ and $25.00 \mathrm{~mm}$ respectively. The data are obtained at the same conditions of the positive lenses in Fig.5.

\subsection{Real-Life Context Based Approach}

The essential part of learning physics is to analyze the physical world we live $\mathrm{in}^{12}$. In this way, the new concepts learners gain should be synthesized with their existing concepts by considering their experiences, attitudes and beliefs. Students often learn to set complex mathematical equations and solve the problems in a short time but they fail at understanding physical concepts behind the problem and explaining the solution in a physical aspect ${ }^{13}$.

As explained in ref. 2, the context based learning is to relate teaching to real life based applications in order to make learning significant. A spectrum of approaches using context based learning exist using illustrative applications at one end of the spectrum and scenarios involving the students at the other.

Context based teaching can be effective at solving problems in which the subject is very difficult, irrelevant and boring, and extensive evidence that students are generally unable to correctly apply the concepts of physics to common everyday situations in physics education. Thus, students may apply the physics laws to daily life situations by using some methods and materials ${ }^{14}$. The most important characteristics of teaching supported with materials is that teaching becomes attractive, fluent, efficient, economic and enriched ${ }^{15}$. 
Contexts act as a "bridge" for learning the related science concepts in context-led advanced science courses such as optical lens design. In more conventional concept-led courses, applications and contexts are used to illustrate the science rather than being the central framework for the curriculum. According to Mary Ratcliffe, concepts are tools for thinking and contexts are a way of setting up arguments, explanations and installing concepts, packages in students' heads ${ }^{16}$.

In the literature, there are several studies dealing with real-life context based approach and these studies indicate the benefits of the approach ${ }^{3,14,17,18,19}$.

\section{REAL-LIFE CONTEXT BASED THICK LENS DESIGN LESSON OUTLINE}

Thick lens design lesson which is an important topic of optics education is appropriate for the students who graduated from physics department. Before teaching this topic, it is assumed that students have prerequisite learnings such as nature of light, geometrical optics and its laws, and paraxial approach. Depending on these limitations, a new thick lens design lesson outline is devised in five sections. These sections are introduction, development, elaboration, application, and evaluation.

In the introduction section (Table 1), there are two parts which aim to attract attention, promote thinking and curiosity. In the first part, optical systems such as lenses, binoculars, telescopes, objectives, and eyepieces are used in order to attract students' attention. In the second part, the aberrations of images are found out and the possible causes of aberrations are discussed. Then, the Seidel Aberrations of images are determined in order to promote thinking and curiosity. If rays from a object point are traced through the system and up to the exit pupil such that each one travels an optical path length equal to that of the chief ray, the surface passing through their end points is called the system wavefront for the object point under consideration. If the wavefront is spherical, with its center of curvature at the Gaussian image point, we say that the image is perfect. If, however, the actual wavefront deviates from this Gaussian spherical wavefront, called the Gaussian reference sphere, we say that the image is aberrated ${ }^{6}$. The methods of reducing these aberrations to a minimum, and thereby permitting the formation of reasonably satisfactory images, are one of the chief problems of geometrical optics $^{20}$.

Table 1. The introduction section of the lesson outline of the real-life context based thick lens design.

\begin{tabular}{|c|c|c|c|c|}
\hline$\underline{\text { Part }}$ & $\underline{\text { Teachers' Role }}$ & $\underline{\text { Explanation }}$ & $\underline{\text { Purpose }}$ & $\begin{array}{l}\text { Teaching } \\
\text { Techniques and } \\
\underline{\text { Methods }}\end{array}$ \\
\hline 1 & $\begin{array}{l}\text { Instructor enters the classroom with } \\
\text { different kinds of optical systems. }\end{array}$ & $\begin{array}{l}\text { Optical systems such as lenses, } \\
\text { binoculars, telescopes, objectives, } \\
\text { and eyepieces are used. }\end{array}$ & Gain attention & - \\
\hline 2 & $\begin{array}{l}\text { Instructor asks questions about optical } \\
\text { systems. If there is no participation, } \\
\text { instructor guides students. } \\
\text { Students are supposed to use the optical } \\
\text { systems. }\end{array}$ & $\begin{array}{l}\text { Lens parameters which are used in } \\
\text { the optical systems are determined. } \\
\text { The aberrations of images are } \\
\text { found out and the possible causes } \\
\text { of aberrations are discussed. }\end{array}$ & Promote thinking & Guided discussion \\
\hline
\end{tabular}

In the development section (Table 2), the importance of the aberrations of the optical systems is discussed. Lenses are examined as a single lens and as a group in order to determine their aberrations. According to Smith, it is important to note that the term lens is meant to include systems with mirrors as well, and that designs include performance evaluation and fabrication/tolerancing issues ${ }^{1}$. In this section, the instructor uses guided discussion, inquiry and brainstorming teaching techniques in order to promote thinking, and to lead students making observation and analyzing. 
Table 2. The development section of the lesson outline of the real-life context based thick lens design

\begin{tabular}{|c|c|c|c|c|}
\hline$\underline{\text { Part }}$ & Teachers' Role & $\underline{\text { Explanation }}$ & $\underline{\text { Purpose }}$ & $\begin{array}{l}\text { Teaching } \\
\text { Techniques and } \\
\text { Methods }\end{array}$ \\
\hline 1 & $\begin{array}{l}\text { Instructor asks about the instruments and } \\
\text { optical elements which are available in } \\
\text { optical systems. }\end{array}$ & $\begin{array}{l}\text { The importance of the aberrations } \\
\text { of the optical systems is discussed. }\end{array}$ & Promote thinking & Guided discussion \\
\hline 2 & $\begin{array}{l}\text { Students are supposed to examine the } \\
\text { lenses in the optical systems. }\end{array}$ & $\begin{array}{l}\text { Lenses are examined as a single } \\
\text { lens and as a group in order to } \\
\text { determine their aberrations. }\end{array}$ & Observation & Inquiry \\
\hline 3 & $\begin{array}{l}\text { Instructor asks what the characteristics of } \\
\text { lenses should be in the optical systems. }\end{array}$ & & Analysis & Brainstorming \\
\hline
\end{tabular}

In the elaboration section (Table 3), there are three parts. In the first part, the instructor explained thin lens approximation, Coddington shape factor and Coddington position factor with lecturing method. In the second and third part, the changes of the spherical aberrations are examined depending on Coddington shape factors using different optical glasses in the case of thin lens approximation. Then, the same work is applied to the thick lenses with the exact ray tracing by using the optical softwares such as ZEMAX EE. Subsequently, the manufacturing steps of lenses are presented. The manufactured lenses are controlled with test-plates. In the second and third part of the elaboration section, the instructor used brainstorming and computer-aided teaching techniques to make students correlate and elaborate thin lens approximation and thick lens design. Prior to embarking on an extensive tolerance analysis, the design needs to be completed and finalized. One of the very last steps in this process is that of matching radii to existing test plates or tooling. Virtually all optical shops have in their inventory hundreds of so-called test plates. These test plates (sometimes called test glasses) are a convex and concave mating pair of tooling with radii ranging from very short to very long. They are often made of low-expansion Pyrex glass, they have very low surface irregularity, and their radii have been measured to a high level of precision ${ }^{4}$. In recent times, in the manufacturing of lenses, lens testing has been made easy by interferometers using the surface test software.

Table 3. The elaboration section of the lesson outline of the real-life context based thick lens design

\begin{tabular}{|c|c|c|c|c|}
\hline$\underline{\text { Part }}$ & $\underline{\text { Teachers' Role }}$ & $\underline{\text { Explanation }}$ & Purpose & $\begin{array}{l}\text { Teaching } \\
\text { Techniques and } \\
\text { Methods }\end{array}$ \\
\hline 1 & $\begin{array}{l}\text { Instructor presents thin lens } \\
\text { approximation. }\end{array}$ & $\begin{array}{l}\text { Thin lens approximation, } \\
\text { Coddington shape factor and } \\
\text { Coddington position factor are } \\
\text { defined analytically. }\end{array}$ & $\begin{array}{l}\text { Theoretical } \\
\text { explanation }\end{array}$ & Lecturing \\
\hline 2 & $\begin{array}{l}\text { Instructor presents the correlation of thin } \\
\text { lens approximation to thick lens design. }\end{array}$ & $\begin{array}{l}\text { The changes of the spherical } \\
\text { aberrations are examined } \\
\text { depending on Coddington shape }\end{array}$ & Correlation & Brainstorming \\
\hline 3 & $\begin{array}{l}\text { Instructor presents thick lens design as } \\
\text { the variations of spherical aberrations } \\
\text { with Coddington shape factors by using } \\
\text { optical software ZEMAX EE. Instructor } \\
\text { used the Universal Optical Test Station } \\
\text { OptiSpheric to obtain accurate test } \\
\text { results of almost all optical parameters } \\
\text { such as effective focal length, } \\
\text { modulation transfer function, back focal } \\
\text { length, radius of curvature, and flange } \\
\text { focal length. }\end{array}$ & $\begin{array}{l}\text { factors using different optical } \\
\text { glasses in the case of thin lens } \\
\text { approximation. Then, the same } \\
\text { work is applied to the thick lenses } \\
\text { with the exact ray tracing. The } \\
\text { manufacturing steps of lenses are } \\
\text { examined. The manufactured lenses } \\
\text { are controlled with the } \\
\text { interferometer using surface test } \\
\text { software and test-plates. }\end{array}$ & Elaboration & $\begin{array}{l}\text { Computer-aided } \\
\text { teaching }\end{array}$ \\
\hline
\end{tabular}

In the application section (Table 4), students are supposed to design a flowchart showing the attainments of thin lens approximation and thick lenses as a small group activity. Then, students prepares a lens design considering that the designed lens has minimum spherical aberration with zero coma by using application teaching technique. Students follow the lens design and optimization procedure steps prepared by Robert Fischer as an example in the Fig. $8^{4}$. 
Table 4. The application section of the lesson outline of the real-life context based thick lens design

\begin{tabular}{|c|c|c|c|c|}
\hline$\underline{\text { Part }}$ & Teachers' Role & $\underline{\text { Explanation }}$ & $\underline{\text { Purpose }}$ & $\begin{array}{l}\text { Teaching } \\
\text { Techniques and } \\
\text { Methods }\end{array}$ \\
\hline 1 & $\begin{array}{l}\text { Students are supposed to design a } \\
\text { flowchart summarizing the subject. }\end{array}$ & $\begin{array}{l}\text { The attainments of thin lens } \\
\text { approximation and thick lenses are } \\
\text { summarized in the flowcharts. }\end{array}$ & $\begin{array}{l}\text { Review of the } \\
\text { lesson }\end{array}$ & Small group activity \\
\hline 2 & $\begin{array}{l}\text { Instructor expects students to prepare a } \\
\text { lens design. }\end{array}$ & $\begin{array}{l}\text { Students consider that the designed } \\
\text { lens has minimum spherical } \\
\text { aberration. }\end{array}$ & Evaluation & Application \\
\hline
\end{tabular}

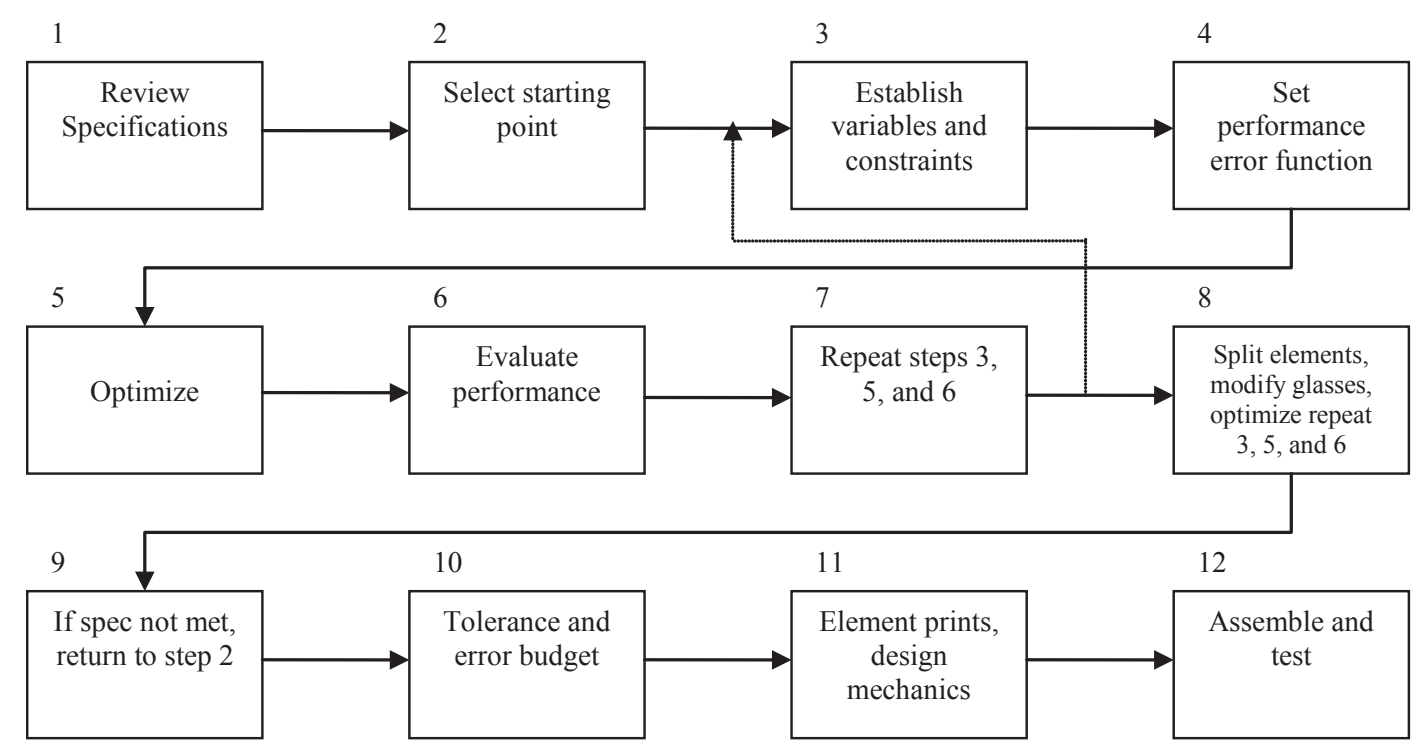

Figure 8. Lens design and optimization procedure.

In the evaluation section (Table 5), the instructor expects students to prepare a concept map showing concepts of the subject and relations between them as homework in order to evaluate the understanding of the students.

Table 5. The evaluation section of the lesson outline of the real-life context based thick lens design

\begin{tabular}{|lllll}
\hline$\underline{\text { Part }}$ & $\underline{\text { Teachers' Role }}$ & $\underline{\text { Explanation }}$ & Purpose & $\begin{array}{l}\text { Teaching } \\
\text { Techniques and } \\
\text { Methods }\end{array}$ \\
1 & $\begin{array}{l}\text { Instructor expects students to prepare a } \\
\text { concept map showing the concepts of the } \\
\text { subject and the relations between them. }\end{array}$ & $\begin{array}{l}\text { Students attainments are } \\
\text { discovered by the concept maps. }\end{array}$ & Evaluation & Homework \\
\hline
\end{tabular}

A Universal Optical Test Station called "OptiSpheric" manufactured by Trioptics GmbH Optische Instrumente Hafenstr. 39 D-22880 Wedel, Germany is used to completely measure and qualify optical components and systems. OptiSpheric is a fully automated optical test station featuring accurate performance characterization of optical components and lens systems. It provides test results of optical parameters such as effective focal length, modulation transfer function, back 
focal length, radius of curvature, and flange focal length. This optical test station shows where the manufacturing process needs improvement and becomes an indispensable tool for quality assurance in the optical shop or for the research work in the optical design education.

\section{CONCLUSIONS}

Thin lens approximation is a useful and advantageous approach for single lens design to investigate definitions, identifications and characterisations of aberrations. Therefore, in this study, aberration functions and conditions have been illustrated with Coddington factors. If the exit pupil is at the lens, Coddington factors are operative parameters in spherical aberration and coma functions. The minimization of spherical aberrations can be achieved by using the main parameters of Coddington factors, providing that coma has the minimum quantity which may be compensated in the optical system.

The essential procedure for the determination of transverse ray aberrations is the ray tracing method. Considering this circumstance, as observed by ray tracing, the dependence of spherical aberration on CSF values was discussed. To minimize the spherical aberration accompanying the lens is the basis of the lens design. Consequently, in this study, it is explained that the minimization of aberrations can be taught as a correlation of thin lens approximation to thick lens design in optics education.

Thin lens approximation and thick lens design are generally taught with only lecturing method. But especially, thick lens design is closely related to the real life. Hence, it is more appropriate to teach the thin lens approximation and thick lens design with real-life context based approach. Real-life contexts has a linkage characteristic between the concepts in students' minds arising from their background experiences and the new difficult science concepts such as optical lens design. The real-life context based lessons differ from conventional lessons in the usage of the context. In the real-life context based lessons, contexts are used as the starting point of the subject for the engagement of students' background knowledge to the scientific knowledge. Therefore, the outline of real-life context based thick lens design lesson considering thin lens approximation is applied and explained in detail. In the reflection of the outcomes of previous studies in which context based approach was used, it was found that this new real-life context based thick lens design outline makes more sense, attainments, and retention than traditional thick lens design instructions.

\section{REFERENCES}

[1] Smith, G. H., Practical computer-aided lens design, Willman-Bell, Inc., Richmond, Virginia, USA, Papers 3 (1998).

[2] Whitelegg, E. and Parry, M., "Real-life contexts for learning physics: meanings, issues and practice", Physics Education, Papers 34(2), 68-72 (1999).

[3] Hill, A. M., "Problem solving in real-life context: an alternative for design in technology education", International Journal of Technology and Design Education, Papers 8, 203-220 (1998).

[4] Fischer, R. E. \& Tadic-Galeb, B., [Optical System Design], McGraw-Hill, Spie Press, USA, 63-172 (2000).

[5] Mahajan,V. N., Aberration Theory Made Simple, SPIE Optical Engineering Press, Bellingham, Washington, 3-27 (1991).

[6] Mahajan,V. N., Optical Imaging and Aberrations Part I, SPIE Optical Engineering Press, Bellingham, Washington pp. 142, 245-364 (1998).

[7] Kidger, M. C., Principles of Lens Design, Proc. SPIE Vol. CR41, pp. $30-53$ (1991).

[8] Welford,W. T., [Aberrations of Optical Systems], IOP Publishing Ltd., Bristol, pp. 105-128 (1991).

[9] Smith,W. J., [Modern Optical Engineering], 2nd ed. McGraw - Hill, , pp. 57-85 (1990). 
[10] Schott Optical Glass Catalogue, Schott Glaswerke Optisches Glass Hattenbergstraße 10 W-6500 Mainz, Germany (2011).

[11] Farsakoglu, O. F., Zengin, D. M., and Kocabas, H., "A correlation of thin lens approximation to thick lens design by using Coddington factors in lens design and manufacturing”, Turk J Phy, Papers 25, 271-282 (2001).

[12] Posner, J. G., Strike, A. K., Hewson, W. P., and Gertzog, A. W., "Accommodation of a scientific conception: toward a theory of conceptual change", Science Education, Papers 66(2), 211-227 (1982).

[13] Clement, J., “Students' preconceptions in introductory physics”, Am. J. Phys. Papers 50, 66-71 (1981).

[14] Lye, H., Fry, M., and Hart, C., "What does it mean to teach physics 'in context'? A first case study", Australian Science Teachers' Journal, Papers 48(1), 16-22 (2001).

[15] Bodur, E. T., "The effect of constructive approach on student success in the computer assisted physics teaching", Master of Science Thesis, Sakarya University Institute of Social Sciences, (2006).

[16] “CurriculumIssues” URL <www.nuffieldcurriculumcenter.org/go/CurriculumIssues/Issue_370.html>,(15.07.2008)

[17] Vignouli, V., Hart, C., and Fry, M., "What does it mean to teach physics 'in context'? A second case study", Australian Science Teachers' Journal, Papers 48(3), 6-13 (2002).

[18] Bennett, J. and Lubben, F., "Context-based chemistry: The Salters Approach”, International Journal of Science Education, Papers 28(9), 999-1015 (2006).

[19] O’Connor, C. and Hayden H, “Contextualising nanotechnology in chemistry education”, Chemistry Education Research and Practice, Papers 9, 35-42 (2008).

[20] Jenkins, F. A. \& White, H. E.,[Fundamentals of optics], 4th ed. McGraw-Hill International Editions, Singapore, pp. 149 (1976). 